\title{
Rancang Bangun Antena Yagi 433 Mhz pada Automatic Antenna Tracker untuk Pesawat Terbang Tanpa Awak
}

\author{
Denny H.T. Nugroho ${ }^{1}$, M. Farid Hasan ${ }^{2}$ \\ 1,2 Program Studi Teknik Elektro, Institut Teknologi Sumatera \\ *denny.nugroho@el.itera.ac.id 1, mfarid.13115012@student.itera.ac.id 2
}

\begin{abstract}
Small Scale Mapping Sector uses UAV (Unmanned Aerial Vehicle) as a mapping tool. UAVs require wireless and longdistance communication. For this reason, an antenna with a far beam pattern and a high gain are needed. This research uses the Yagi antenna because it has a directional beam pattern but has a weakness that is, the Yagi antenna must be directed by pointing to connect the communication between the antenna and the UAV. Based on the results of the calculation and simulation of the Yagi antenna with a frequency of $433 \mathrm{MHz}$, a gain of 14.2 dBi was obtained. Yagi antenna designs are made using aluminum and copper. From the results of the communication distance test, obtained a range of $\pm 5 \mathrm{~km} . T h e$ test is carried out by attaching the Yagi antenna to the receiver of the $433 \mathrm{MHz}$ telemetry module, then the transceiver module is installed in the $U A V$.
\end{abstract}

Keywords : Antenna, Yagi antenna, Wireless communication, Unmanned aerial vehicle, Telemetry

\section{INTISARI}

Bidang pemetaan lahan skala kecil menggunakan UAV (Unmanned Aerial Vehicle) sebagai sarana pemetaan. UAV memerlukan komunikasi tanpa kabel (wireless) dengan jarak yang jauh dan stabil. Untuk itu dibutuhkan sebuah antena dengan pola pancaran yang jauh dan penguatan ( gain) yang tinggi. Penelitian ini menggunakan antena Yagi karena memiliki pola pancaran yang terarah (directional) tetapi memilki kelemahan yaitu, antena Yagi harus diarahkan secara pointing untuk menjaga komunikasi antara antena dan UAV. Berdasarkan hasil perhitungan dan simulasi antena Yagi dengan frekuensi $433 \mathrm{MHz}$, diperoleh penguatan (gain) sebesar 14,2 dBi. Rancangan antena Yagi dibuat menggunakan Almunium dan tembaga berbentuk pipa. Dari hasil pengujian jarak komunikasi diperoleh jarak jangkauan $\pm 5 \mathrm{~km}$. Pengujian dilakukan dengan memasangkan antena Yagi ke modul receiver telemetri $433 \mathrm{MHz}$, kemudian modul transceiver dipasang pada pesawat tanpa awak (UAV) yang diterbangkan.

Kata kunci: antena, antena Yagi, komunikasi wireless, pesawat tanpa awak, telemetri

\section{PENDAHULUAN}

Pada bidang pemetaan lahan, informasi merupakan hal yang sangat vital, karena digunakan untuk mengetahui lokasi, ketinggian UAV serta untuk mengetahui kondisi UAV sehingga stasiun penerbangan atau Ground Control Station (GCS) dapat mengambil keputusan apakah UAV tersebut tetap bisa melakukan penerbangan (flight) atau pendaratan (landing). Maka dari itu, komunikasi antar UAV dengan GCS harus dalam kondisi yang baik alias tanpa gangguan.
Komunikasi antara UAV dengan GCS merupakan komunikasi jarak jauh tanpa kabel (wireless). Oleh sebab itu, membutuhkan sebuah antena dengan jarak jangkauan komunikasi yang jauh. Ada bermacam-macam jenis antena yang biasa digunakan, seperti antena dipole, antena helical, antena parabolik, antena Yagi, antena moxon, dan lain-lain. Berbeda jenis antena, berbeda pula bentuk atau pola pancarannya. Ada jenis pancaran omni-directional (segala arah), bidirectional (dua arah), dan directional (searah)[1][2]. Berdasarkan kebutuhan, dimana antena harus memiliki jarak jangkauan 
Jurnal ECOTIPE, Volume 7, No.1, April 2020, Hal. 20-25

p-ISSN 2355-5068, e-ISSN 2622-4852

Akreditasi Kemenristekdikti (SINTA 4), SK. No.10/E/KPT/2019

DOI: 10.33019/ecotipe.v7i1.1390

komunikasi yang jauh dengan daya input sebesar $100 \mathrm{~mW}$, maka dirancanglah sebuah antena Yagi yang memiliki pola pancaran yang lurus dan terarah (directional), karena dengan pola pancaran yang lurus dapat mencapai jarak yang jauh, tergantung dari daya input yang dipancarkan serta besar nilai penguatan dari antena tersebut.

Antena yang memiliki pola pancaran yang lurus atau terarah memiliki kelemahan yaitu harus selalu diarahkan untuk menjaga komunikasi antara antena dan UAV tetap stabil, jika sampai meleset atau melenceng akan menyebabkan komunikasi antara antena dan UAV akan terputus. Untuk mengatasi hal tersebut, antena Yagi yang dirancang akan dipasangkan pada sebuah alat pelacak otomatis (Automatic Tracker) supaya antena Yagi dapat mengarah ke UAV (pointing) secara terus-menerus (real-time).

\section{LANDASAN TEORI}

\section{A. Antena Yagi}

Antena Yagi merupakan salah satu dari berbagai macam antena yang memiliki pola pancaran yang lurus dan terarah (directional). Antena Yagi ditemukan oleh Professor Hidetsugu Yagi dan Assistennya Shintaro Uda pada tahun 1925. Antena Yagi merupakan sebuah antena dipole yang diberi tambahan parasitic elements berupa reflector dan director sehingga menghasilkan gain ke arah tertentu [2].

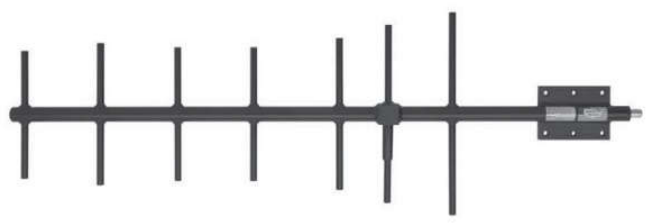

Gambar 1. Bentuk Antena Yagi

Antena Yagi memiliki komponen/elemen utama yaitu elemen dipole yang merupakan pemancar radiasi utama. Kemudian elemen reflektor yang merupakan elemen pemantul radiasi agar pola pancaran mengarah ke depan (ujung kiri Gambar 1). Komponen yang terakhir ada elemen penyearah (director) yang digunakan sebagai penyearah pola pancaran dan menyempitkan sudut pancaran, semakin banyak elemen director yang terpasang, pola radiasi akan semakin sempit dan semakin jauh.

\section{B. Rumus Dasar Antena Yagi}

Dalam perancangan antena Yagi terdapat rumus dasar yang digunakan, yaitu: $\lambda=c / f$. Dimana $\lambda$ adalah panjang gelombang yang digunakan untuk menentukan panjang tiap komponen/elemen antena Yagi. Serta $c$ adalah cepat rambat cahaya $\left(3 \times 10^{8} \mathrm{~m} / \mathrm{s}\right)$ dan $f$ adalah frekuensi kerja yang digunakan pada antena [3]. Kemudian dari penentuan panjang gelombang pada antena akan dapat ditentukan panjang tiap komponen atau elemen antena dengan menggunakan rumus pada Tabel 1 .

Tabel 1.Rumus Panjang Setiap Elemen Antena Yagi

\begin{tabular}{|l|l|}
\hline$l$ dip $=0.5 \times K \times \lambda$ & $\begin{array}{l}\text { ldip: panjang dipole } \\
\text { driven, } \mathrm{K}=0,96\end{array}$ \\
\hline$l \operatorname{Re} f=0.55 \times K \times \lambda$ & $\begin{array}{l}\text { l Ref }: \text { panjang } \\
\text { Reflektor }\end{array}$ \\
\hline$l \operatorname{Dir} 1=l$ dip $-(5 \% l$ dip $)$ & $\begin{array}{l}\text { l Dir : panjang } \\
\text { Director }\end{array}$ \\
\hline$l \operatorname{Dir} 2=l \operatorname{dir} 1-(5 \% l$ dir 1$)$ & $\begin{array}{l}\text { rumus ini digunakan } \\
\text { hingga director } \\
\text { selanjutnya }\end{array}$ \\
\hline
\end{tabular}

Sedangkan untuk rumus perhitungan jarak antar komponen serta penguatan (gain) tiap komponen terdapat pada Tabel 2.

Tabel 2. Rumus Jarak Antar Elemen Antena Yagi

\begin{tabular}{|c|l|}
\hline dipref $=0.225 \times \lambda$ & $\begin{array}{l}\text { dipref : jarak } \\
\text { antara dipole dan } \\
\text { reflektor }\end{array}$ \\
\hline dipdir1 $=0.125 \times \lambda$ & $\begin{array}{l}\text { dipdir1 : jarak antara } \\
\text { dipole dan director 1 }\end{array}$ \\
\hline dir1dir2 $=0.175 \times \lambda$ & $\begin{array}{l}\text { dir1dir2 : jarak } \\
\text { antara director 1 dan } \\
\text { director 2 }\end{array}$ \\
\hline $\operatorname{dir} 2$ dir $3=0.225 \times \lambda$ & $\begin{array}{l}\text { dir2dir3 : jarak } \\
\text { antara director 2 dan } \\
\text { director 3 }\end{array}$ \\
\hline
\end{tabular}


Jurnal ECOTIPE, Volume 7, No.1, April 2020, Hal. 20-25

p-ISSN 2355-5068, e-ISSN 2622-4852

Akreditasi Kemenristekdikti (SINTA 4), SK. No.10/E/KPT/2019

DOI: 10.33019/ecotipe.v7i1.1390

Kaidah-kaidah dasar pembuatan antena digunakan untuk menentukan penguatan (gain) antena. Berikut kaidah yang digunakan [4]:

1. Setiap antena dipole $\frac{1}{2} \lambda$ mempunyai gain sebesar 2,1 dBi

2. Setiap antena dipole $\frac{1}{2} \lambda$ yang diberi elemen parasitik berupa elemen director dan reflektor akan ditambah gain sebesar $5 \mathrm{~dB}$ dari sebelumnya.

3. Saat sudah terpasang director 1 lalu dipasang director 2, 3, dan seterusnya, akan menunjukkan penurunan penambahan gain. Tambahan director 2 menambahkan gain sebesar $2 \mathrm{~dB}$ dari sebelumnya. Tambahan director 3 dan 4 menambahkan gain sebesar 1 $\mathrm{dB}$ dari sebelumnya. Tambahan director 5 dan seterusnya, penambahan gain tidak terlalu terlihat.

4. Jika dipakai elemen reflektor dan director bersama-sama pada sebuah antena, gain dari reflektor yang semula sebesar $5 \mathrm{~dB}$ akan dihitung sebesar $3 \mathrm{~dB}$ saja.

\section{METODE PENELITIAN}

Penelitian rancang bangun antena Yagi 433 $\mathrm{MHz}$ pada automatic antenna tracker untuk pesawat terbang tanpa awak dilakukan beberapa tahapan, seperti: perhitungan antena secara manual, perhitungan menggunakan Yagi calculator, simulasi menggunakan software, dan implementasi.

\section{A. Perhitungan Antena Secara Manual}

Perhitungan yang dilakukan adalah menghitung panjang dan jarak setiap elemen antena Yagi dengan menggunakan rumus $\lambda=\frac{c}{f}$, dimana $c=3 \times 10^{8} \mathrm{~m} / \mathrm{s}, f=$ frekuensi kerja pada antena, $\lambda=$ panjang gelombang. Dari panjang gelombang tersebut, diperoleh panjang disetiap elemen antena Yagi. Antena Yagi memiliki beberapa elemen, yaitu elemen reflektor, elemen driven, dan elemen director. Dimana $k$ adalah velocity factor, untuk tembaga menggunakan nilai 0,96 [5].

\section{B. Perhitungan Menggunakan Yagi Calculator \\ Untuk menggunakan software Yagi} Calculator cukup memasukkan frekuensi kerja antena Yagi yang akan dibuat, lalu memasukkan diameter elemen antena, jumlah elemen, nilai velocity factor, bentuk elemen. Kemudian klik "calculate" untuk melihat hasilnya, kemudian dibandingkan dengan hasil perhitungan manual.

\section{Simulasi Antena Yagi}

Software ini dapat digunakan untuk mensimulasikan segala jenis antena. Dari simulasi tersebut dapat ditampilkan hasil berupa pola radiasi (pancaran), gain (penguatan), bandwidth, beamwidth, return loss, Voltage Standing Wave Ratio (VSWR).

\section{Implementasi}

Implementasi antena Yagi $433 \mathrm{MHz}$ pada automatic antenna tracker untuk pesawat terbang tanpa awak menggunakan bahan almunium dan tembaga. Adapun ukuran dan tata letak reflector serta director berdasarkan perhitungan manual dan simulasi (Gambar 2).

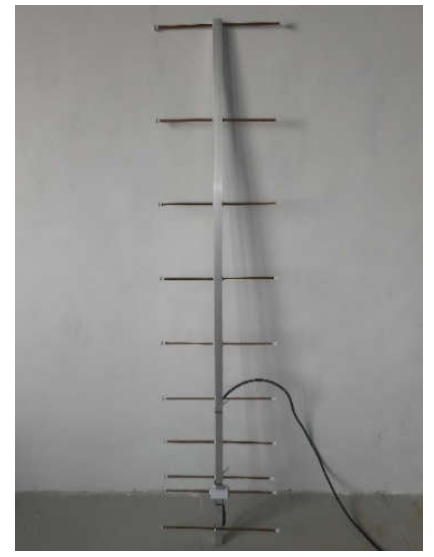

Gambar 2. Implementasi rancang bangun antena Yagi $433 \mathrm{Mhz}$. 
Jurnal ECOTIPE, Volume 7, No.1, April 2020, Hal. 20-25

p-ISSN 2355-5068, e-ISSN 2622-4852

Akreditasi Kemenristekdikti (SINTA 4), SK. No.10/E/KPT/2019

DOI: 10.33019/ecotipe.v7i1.1390

\section{HASIL PENELITIAN DAN PEMBAHASAN}

Data awal yang perlu didapatkan adalah data hasil perhitungan antena Yagi, baik ukuran maupun penguatannya. Tabel 3 menunjukkan hasil perhitungan antena secara manual.

Tabel 3. Hasil perhitungan manual antena Yagi

\begin{tabular}{|c|c|c|c|}
\hline Komponen & $\begin{array}{c}\text { Panjang } \\
(\mathbf{c m})\end{array}$ & $\begin{array}{c}\text { Jarak } \\
(\mathbf{c m})\end{array}$ & $\begin{array}{c}\text { Total Gain } \\
(\mathbf{d B i})\end{array}$ \\
\hline Reflektor & 36,6 & 15,6 & 2,1 \\
\hline Dipole & 33,3 & 0,0 & 4,2 \\
\hline Director 1 & 31,6 & 8,7 & 6,3 \\
\hline Director 2 & 30,0 & 12,1 & 8,3 \\
\hline Director 3 & 28,5 & 15,6 & 9,3 \\
\hline Director 4 & 27,1 & 15,6 & 10,3 \\
\hline Director 5 & 25,7 & 15,6 & 11,3 \\
\hline Director 6 & 24,4 & 15,6 & 12,2 \\
\hline Director 7 & 23,2 & 15,6 & 13,0 \\
\hline Director 8 & 22,1 & 15,6 & \multirow{2}{*}{$\mathbf{1 3 , 8}$} \\
\hline \multicolumn{3}{|c|}{ Total Gain } \\
\cline { 1 - 2 }
\end{tabular}

Kemudian data perhitungan software Yagi Calculator, dimana data ini digunakan sebagai referensi dari hasil perhitungan manual. Tabel 4 menunjukkan data hasil Yagi calculator.

Tabel 4. Hasil Yagi calculator

\begin{tabular}{|c|c|c|c|}
\hline Komponen & $\begin{array}{c}\text { Panjang } \\
(\mathbf{c m})\end{array}$ & $\begin{array}{c}\text { Jarak } \\
\text { (cm) }\end{array}$ & $\begin{array}{c}\text { Total Gain } \\
\text { (dBi) }\end{array}$ \\
\hline Reflektor & 35.6 & 13.8 & 2.1 \\
\hline Dipole & 32.3 & 0 & 4.2 \\
\hline Director 1 & 31.5 & 5.2 & 6.3 \\
\hline Director 2 & 31.1 & 12.5 & 8.3 \\
\hline Director 3 & 30.8 & 14.9 & 9.7 \\
\hline Director 4 & 30.5 & 17.3 & 10.9 \\
\hline Director 5 & 30.2 & 19.4 & 11.8 \\
\hline Director 6 & 29.9 & 20.8 & 12.6 \\
\hline Director 7 & 29.7 & 21.8 & 13.2 \\
\hline Director 8 & 29,5 & 22.8 & \multirow{2}{*}{ Total gain } \\
\hline \multicolumn{3}{|c|}{} \\
\hline
\end{tabular}

Terlihat dari Tabel 3 dan 4 nilai yang diperoleh tidak jauh berbeda antara hasil perhitungan manual dan software Yagi calculator, dari data di atas yang dibandingkan adalah panjang elemen, jarak antar elemen, dan gain. Perhitungan dengan software Yagi calculator digunakan untuk memastikan apakah nilai hasil perhitungan manual tersebut sudah benar.

Selanjutnya dari data tersebut digunakan sebagai parameter simulasi antena. Pada simulasi antena beberapa data yang dihasilkan adalah pola pancaran antena, gain, bandwidth, VSWR, dan Return Loss.

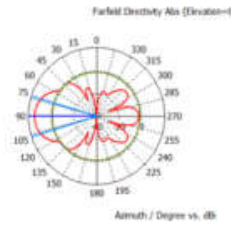

(a)

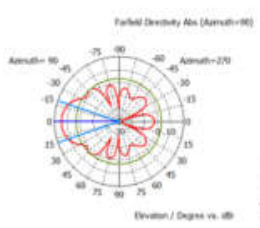

(b)
Gambar 3. a) Pola pancaran pada sumbu elevasi. b) Pola pancaran pada sumbu azimut

Gambar 3a) dan 3b) menunjukkan pola radiasi dari antena Yagi pada sumbu elevasi dan azimut. Pada sumbu elevasi didapatkan beamwidth 34.1 deg dan gain $14.2 \mathrm{~dB}$. Sedangkan pada sumbu azimut didapatkan beamwidth 37.4 deg dan gain $14.2 \mathrm{~dB}$. Terlihat bahwa terdapat sedikit perbedaan gain antara simulasi dan perhitungan sebesar 0.4.

Data selanjutnya yang perlu dilihat adalah $S$ parameter dan lebar bandwidth, dimana $S$ parameter ini berisi VSWR, dan return loss. Berikut data S-parameter dan lebar Bandwidth:

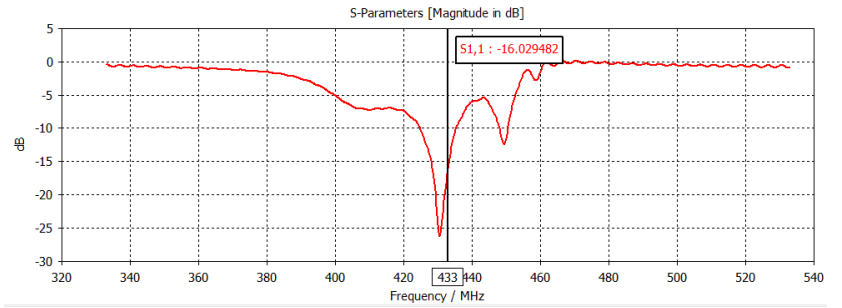

Gambar 4. Nilai return loss yang diperoleh dari simulasi

Nilai return loss yang diperoleh dari simulasi sebesar $-16,02 \mathrm{~dB}$, nilai ini sudah termasuk baik dalam mendesain sebuah antena. Karena syarat dikatakan sebuah antena dapat bekerja dengan baik adalah nilai return loss-nya lebih kecil dari $10 \mathrm{~dB}$ [6]. Kemudian nilai lebar bandwidth yang 
Jurnal ECOTIPE, Volume 7, No.1, April 2020, Hal. 20-25

p-ISSN 2355-5068, e-ISSN 2622-4852

Akreditasi Kemenristekdikti (SINTA 4), SK. No.10/E/KPT/2019

DOI: 10.33019/ecotipe.v7i1.1390

diperoleh merupakan hasil perhitungan, yaitu $0.03 \%$.

Nilai VSWR yang diperoleh dari hasil simulasi adalah sebesar 1,3752035 $\approx 1,38$ (gambar 5). Nilai tersebut sudah termasuk baik dalam pembuatan sebuah antena, karena syarat nilai VSWR yang digunakan dalam pembuatan antena adalah $1<$ Nilai VSWR $<2$. Dalam proses mendapatkan nilai VSWR, gain, return loss yang baik serta nilai frekuensi yang sesuai, dibutuhkan penyesuaian ukuran panjang elemen antena dan jarak antar elemen.

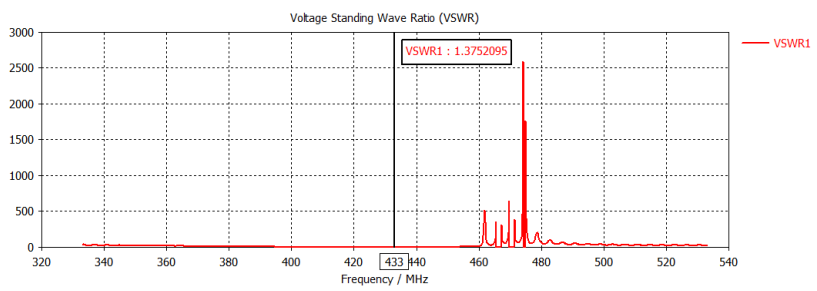

Gambar 5. Simulasi nilai VSWR

Setelah data simulasi antena didapatkan dengan parameter nilai yang baik, antena dibuat dengan menggunakan bahan almunium dan pipa tembaga (Gambar 2). Kemudian antena diuji dengan menggunakan UAV dan software mission planner (Gambar 6).

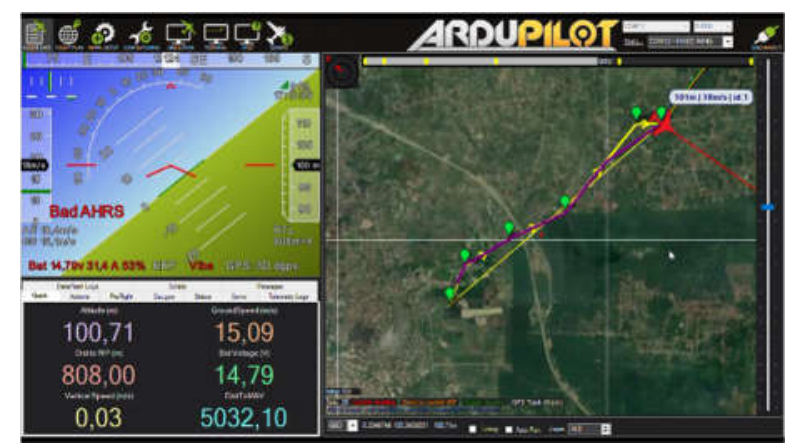

Gambar 6. Tampilan pengukuran jarak antena Yagi

Dari pengujian jarak komunikasi antena Yagi terlihat bahwa jarak maksimum komunikasi antena adalah $5032,10 \mathrm{~m} \approx 5 \mathrm{~km}$ dengan kekuatan sinyal $30 \%$ dan penguatan $0,11 \mathrm{dBi}$ (Gambar 7). Jarak tersebut dapat dipertanggungjawakan, karena jarak tersebut sudah diukur dengan menggunakan koordinat GPS pada titik-titik tersebut.

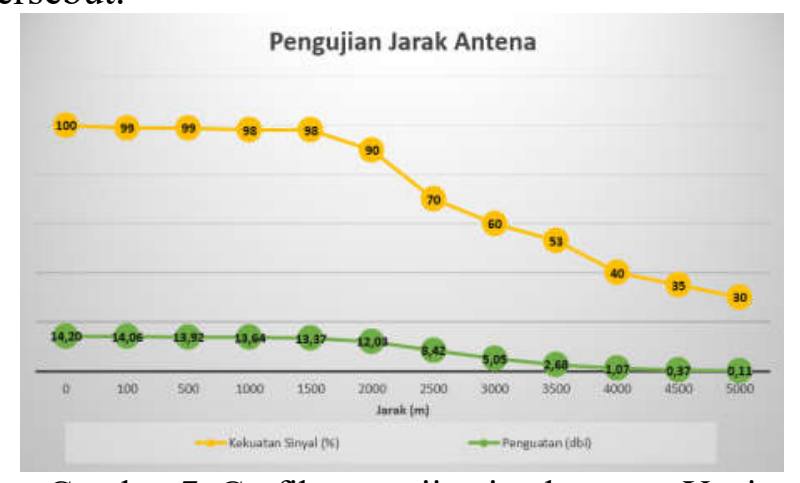

Gambar 7. Grafik pengujian jarak antena Yagi terhadap kekuatan sinyal dan penguatan

\section{KESIMPULAN}

Rancang bangun antena Yagi $433 \mathrm{Mhz}$ pada automatic antenna tracker pesawat terbang tanpa awak telak dilakukan dan memenuhi persyaratan yang diinginkan pada aplikasi antena. Dari hasil simulasi dan pengujian didapat penguatan antena sebesar 14,2 dBi dengan jarak jangkauan komunikasi mencapai $\pm 5 \mathrm{~km}$.

\section{ACKNOWLEDGMENT}

Riset ini didukung secara finansial oleh Institut Teknologi Sumatera dengan dana hibah penelitian mandiri ITERA 2018.

\section{DAFTAR PUSTAKA}

[1] Deden. N. R, Arsyad. R. D, Lita. Lidyawati, "Impelementasi Antena Yagi 5 Elemen Sebagai Penerima Siaran Televisi di Bandung Kota".(2016).JETT.

[2] Soleh, Muhammad. 2012. Perancangan Antena Yagi Uda Pada Frekuensi $600 \mathrm{MHz}$, Semarang : Teknik Elektro Undip.

[3] Ridwan Lesmana, "ANTENA YAGI untuk 2 m Band," pp. 1-8, 1925.

[4] E. S. dan R. Widianto, "Perancangan Antena Mikrostrip Yagi pada Frekuensi Kerja 1,9-2,1 GHz," pp. 151-157, 2017.

[5] Fauzi.D.L.N, dan T Hariyadi, "Design of a Directional Microstrip Antenna at UHF-Band 
Jurnal ECOTIPE, Volume 7, No.1, April 2020, Hal. 20-25

p-ISSN 2355-5068, e-ISSN 2622-4852

Akreditasi Kemenristekdikti (SINTA 4), SK. No.10/E/KPT/2019

DOI: 10.33019/ecotipe.v7i1.1390

for Passive Radar Application”, (2017), ISMEE, Universitas Pendidikan Indonesia.

[6] S.I.Andi, Maria Ulfah, Hadiyanto, "Pengaruh Beamwidth, Gain dan Pola Radiasi Performansi Antena Penerima", 2018, Politeknik Negeri Balikpapan. 